\title{
Magnitude of acute respiratory infections in 6 months- 6 years in a rural hospital in B G Nagara: a cross-sectional study
}

\author{
Shivaprakash $\mathrm{NC}^{1}$, Kutty $\mathrm{DN}^{2}$ \\ ${ }^{1}$ Dr Shivaprakash N.C., HOD of Pediatrics, Adichunchanagiri Institute of Medical Sciences, B.G. Nagara, Nagamangala \\ Taluk, Mandya District, Karnataka, ${ }^{2}$ Dr Divya Narayanan Kutty, Postgraduate, Department of Pediatrics, \\ Adichunchanagiri Institute Of Medical Sciences, B.G. Nagara, Nagamangala Taluk, Mandya District, Karnataka, India.
}

Address for Correspondence: Dr Divya Narayanan Kutty, Email: dichu5985@gmail.com

\begin{abstract}
Background: ARI is a major cause for morbidity and mortality in under five children and is responsible for $30-50 \%$ of all outpatients and $20-40 \%$ of in-patients. The overall incidence may be 5 episodes/child/year accounting for about 238 million attacks. Objectives: To study the prevalence of ARI in 6 months- 6 years children in a rural hospital in B G Nagara. Methods: A cross-sectional study was conducted for a period of one year in a rural hospital. Symptoms of cough, cold, fever, refusal of feeds and hurried breathing were considered to assess an ARI episode. Respiratory rate $>60$ /minute ( $<2$ month infants), $>50$ (2-12 months) and $>40$ (1-5 years) in a child with cough, cold or fever singly or in combination was considered the criteria for recognition of pneumonia. Other parameters like previous episodes, family history of ARI and immunization status were also taken into account. Results: Out of the 145 children with ARI surveyed, $69.7 \%$ had LRTI while $30.3 \%$ had URTI. $63.4 \%$ male children and $36.6 \%$ female children had ARI; male: female ratio being 1.7:1. It was more predominant in the age group of 6-12 months (46.2\%). Out of the 32 children not breast fed, $75 \%$ had LRTI and $25 \%$ had URTI. $31.7 \%$ of the children had previous episodes of ARI while $11 \%$ of the children had positive family history of ARI. Conclusion: An understanding of ARI prevalence and the associated risk factors is essential. There is a significant association between ARI and low socioeconomic status, overcrowding, low birth weight, delay in the initiation of breast feeding, lack of exclusive breast feeding, prelacteal feeding, timely given complementary feeding and immunization status. The importance of basic health promotional measures like proper infant feeding practices, proper nutrition, immunization and improvement in the socioeconomic status help in the control and prevention of ARI.
\end{abstract}

Keywords: ARI, Prevalence, Risk factors, Under-five children

\section{Introduction}

Acute respiratory infections are a major cause of morbidity and mortality in children and of particular significance in developing countries like India [1]. ARI is responsible for an estimated 3.9 million deaths worldwide every year [2]. ARI is responsible for 30$50 \%$ of all outpatients and $20-40 \%$ of in-patients. The overall incidence of acute respiratory infection in the under-5 may be 5 episodes/child/year accounting for about 238 million attacks [2].

In India, in the year 2013, about 31.7 million cases of ARI were reported [3]. Worldwide, about $85-88 \%$ of ARI episodes are Acute Upper Respiratory Infections

Manuscript received: $30^{\text {th }}$ January 2017

Reviewed: $8^{\text {th }}$ February 2017

Author Corrected: $15^{\text {th }}$ February 2017

Accepted for Publication: $21^{\text {st }}$ February 2017
(AURI) while the remaining are Acute Lower Respiratory Infections (ALRI)[4,5]. 90\% of ARI deaths are due to Pneumonia which is mostly bacterial cause. The incidence of Pneumonia in developed countries is $3-4 \%$ while in developing countries is $20-30 \%$ [2]. Pneumonia is responsible for about $18 \%$ of all under five deaths in India [3].

ARI can be classified into 2 types, based on the site of infection, into Acute upper respiratory tract infection (AURI) that includes common cold, pharyngitis, tonsillitis, sinusitis and otitis media while epiglottitis, laryngitis, croup syndrome (acute laryngotracheobronchitis), bronchiolitis and pneumonia are Acute Lower respiratory tract infection (ALRI). The common organisms responsible for causing respiratory 
infections include bacteria and viruses. The most common organism identified is Streptococcus pneumoniae accounting for $30-50 \%$ of pneumonia cases. The second most common organism is being Hemophilus influenza accounting for $10-30 \%$ cases.

The other organisms isolated are Staphylococcus aureus, Klebsiella pneumoniae and Mycobacterium tuberculosis [1]. Among viruses, respiratory syncytial virus is the leading cause, identified in $15-40 \%$ of cases, followed by influenza $\mathrm{A}$ and $\mathrm{B}$, parainfluenza, human metapneumovirus and adenovirus $[1,6,7]$.

Clinical criteria for diagnosis of pneumonia include [1]:

$>$ Rapid Respiration

1. Respiratory rate of $>60$ - below 2 months of age

2. $>50$ - 2months- 1 year

3. $>40$ in $1-5$ years

$>$ Difficulty in respiration is defined as lower chest indrawing.

Various risk factors identified for ARI are malnutrition, lack of immunization, poor breast feeding practices, overcrowding, low birth weight, exposure to air pollution, young age, vitamin A deficiency, passive smoking, family history of respiratory diseases $[6,8]$.

Management of AURI ( No Pneumonia)[9]: Many children with symptoms of cough, cold or fever do not have pneumonia and do not require antibiotics. Majority is caused by viruses and hence antibiotics are not recommended. Symptomatic treatment and home care is sufficient for such cases.

The importance of basic health promotional measures like proper infant feeding practices, proper nutrition, immunization and improvement in the socioeconomic status help in the control and prevention of ARI [10].

Aims and Objectives of the Study: To study about the prevalence of acute respiratory infections (ARI) in 6 months- 6 years children in a rural hospital in B G Nagara.

\section{Materials and Methods}

A cross-sectional hospital based study conducted on the children of age group 6 months- 6 years with ARTI attending a rural hospital in Karnataka from December $1^{\text {st }} 2014$ - November $30^{\text {th }} 2015$. The study was approved by the Institutional Ethical Review Committee. A predesigned proforma has aided in the enrollment of children into the study.
All children between 6 months- 6years of age group were included. Exclusion criteria included cases with chronic respiratory ailments, any congenital defects in the lung, a known case of Pulmonay Tuberculosis and non consenting parents.

The diagnostic criteria included:

- History of nasal discharge, cough, fever, hurried breathing, chest indrawing, refusal of feeds was used to assess an episode of ARI[9];

- Respiratory rate $>60 /$ minute (among $<2$ month infants), $>50$ (2-11 months) and >40 (1-5 years) in a child with cough, cold or fever, singly or in combination are the criteria for recognition of pneumonia [9];

- Previous history of ARI episodes, history of ARI in the family members, the immunization status and diet history was also considered.

- Nutritional status was assessed with parameters like weight, height and mid-arm circumference.

Grade of malnutrition was assessed using the Indian Academy of Paediatrics classification [1]. For malnourished children, mid-arm circumference was also measured ( $>13.5 \mathrm{~cm}$ : normal, $12.5-13.5 \mathrm{~cm}$ : moderate and $<12.5 \mathrm{~cm}$ : severely malnourished)[1].

The children with common respiratory symptoms and signs were admitted for further evaluation and treatment. Routine blood investigations were sent like complete blood counts that included $\mathrm{Hb}$, total counts, differential counts, platelet counts, haematocrit values. Absolute Eosinophil Count (AEC) were done for relevant cases. Chest X-ray was done for all cases. Pulmonary function tests were conducted for diagnosed bronchial asthma cases. Oxygen saturation was checked for all cases.

All the cases over a period of one year were included that comprised of 145 children. Data collection was done using a predesigned proforma.

The data collected was transferred to a master chart and the inference made separately. Data was entered in MS Excel and analysed using SPSS version 20. The data was analysed using the statistical test of significance (Chi-square test). Data was presented in the form of percentage, mean and standard deviation, graphs and figures. $P$ value of $<0.05$ was considered to be statistically significant at $95 \%$ confidence interval. 


\section{Results}

The study included 145 children. And the ARI incidence was calculated according to the number of cases of LRTI and URTI. 101(69.7\%) children had LRTI while only 44 (30.3\%) children had URTI.

Of the 101 children in the present study, 69 (68.4\%) male children and 32 (31.6\%) female children had LRTI. The prevalence of URTI was $23(52.3 \%)$ in male children and $21(47.7 \%)$ in female children out of the 44 children studied. In both cases, male children had higher incidence of LRTI and URTI compared to female children.

TABLE 1: Prevalence of ARI among gender.

\begin{tabular}{|c|c|c|c|c|}
\hline & & Female & Male & Total \\
\hline \multirow{2}{*}{ ARI } & LRTI & $\begin{array}{c}32 \\
(31.6 \%)\end{array}$ & $\begin{array}{c}69 \\
(68.4 \%)\end{array}$ & $\begin{array}{c}101 \\
(100 \%)\end{array}$ \\
\hline & URTI & $\begin{array}{c}21 \\
(47.7 \%)\end{array}$ & $\begin{array}{c}23 \\
(52.3 \%)\end{array}$ & $\begin{array}{c}44 \\
(100 \%)\end{array}$ \\
\hline \multicolumn{2}{|c|}{ Total } & $\begin{array}{c}53 \\
(100.0 \%)\end{array}$ & $\begin{array}{c}92 \\
(100.0 \%)\end{array}$ & $\begin{array}{c}145 \\
(100.0 \%)\end{array}$ \\
\hline
\end{tabular}

The prevalence studied in different age groups. The higher incidence of respiratory infections was observed in the age group of $6-12$ months $(67,46.2 \%)$. The mean age is 2.71 years +2.42 .

TABLE 2: Age wise distribution of patients.

\begin{tabular}{|c|c|c|c|}
\hline \multicolumn{1}{|c|}{} & Frequency & Percent \\
\hline \multirow{4}{*}{ Age groups } & $6-12$ months & 67 & 46.2 \\
\cline { 2 - 4 } & $13-24$ months & 24 & 16.6 \\
\cline { 2 - 4 } & $25-36$ months & 20 & 6.2 \\
\cline { 2 - 4 } & $37-48$ months & 9 & 11.0 \\
\cline { 2 - 4 } & $49-60$ months & 16 & 6.2 \\
\cline { 2 - 4 } & $61-72$ months & 9 & $\mathbf{1 0 0 . 0}$ \\
\hline
\end{tabular}

TABLE 3: Distribution of patients with LRTI and URI in relation to the immunization status

\begin{tabular}{|c|c|c|c|c|}
\hline & & LRTI & URTI & Total \\
\hline \multirow{3}{*}{ Immunization Status } & Complete immunization & $\begin{array}{c}78 \\
(67.8 \%)\end{array}$ & $\begin{array}{c}37 \\
(32.2 \%)\end{array}$ & $\begin{array}{c}115 \\
(100 \%)\end{array}$ \\
\hline & Non immunized & $\begin{array}{c}5 \\
(62.5 \%)\end{array}$ & $\begin{array}{c}3 \\
(37.5 \%)\end{array}$ & $\begin{array}{c}8 \\
(100 \%)\end{array}$ \\
\hline & Partial immunized & $\begin{array}{c}18 \\
(81.8 \%)\end{array}$ & $\begin{array}{c}4 \\
(18.2 \%)\end{array}$ & $\begin{array}{c}22 \\
(100 \%)\end{array}$ \\
\hline \multicolumn{2}{|c|}{ Total } & $\begin{array}{c}101 \\
(100.0 \%)\end{array}$ & $\begin{array}{c}44 \\
(100.0 \%)\end{array}$ & $\begin{array}{c}145 \\
(100.0 \%)\end{array}$ \\
\hline
\end{tabular}

It was observed that $78(67.8 \%)$ children having LRTI and $37(32.3 \%)$ of URTI cases were completely immunized. 18 $(81.8 \%)$ LRTI children and 4 (18.2\%) URTI children were partially immunized. While 5 (62.5\%) LRTI children and 3 
(37.5\%) URTI children were not immunized. In this study, 46 children $(31.7 \%)$ were found to be malnourished. Of which, $31(21.4 \%)$ children belonged to Grade 1.13 children (9.0\%) children belonged to Grade 2 while only 2 (1.4\%) belonged to Grade 4. 67 children (46.2\%) had normal nutritional status while in 32 children $(22.1 \%)$ the malnutrition status could not be assessed as they were below 1 year of age.

TABLE 4: Distribution of malnutrition among ARI.

\begin{tabular}{|c|c|c|c|}
\hline \multicolumn{2}{|c|}{} & Frequency & Percent \\
\hline \multirow{3}{*}{ Malnutrition Status } & Not Required & 32 & 22.1 \\
\cline { 2 - 4 } & Grade 1 & 31 & 21.4 \\
\cline { 2 - 4 } & Grade 2 & 13 & 9.0 \\
\cline { 2 - 4 } & Grade 4 & 2 & 1.4 \\
\cline { 2 - 4 } & Normal & 67 & 100.0 \\
\hline
\end{tabular}

Of the 145 children in the present study, 113 children were exclusively breast fed of which, $77(68.1 \%)$ children had LRTI while 36 (31.9\%) had URTI. 32 children were not exclusively breast fed. Among them 24 (75\%) had LRTI while 8 (25\%) had URTI.

Of the 145 children in the present study, 46 children had history of previous episodes of ARI while 99 had no previous history of ARI episodes. 36 (78.3\%) children with a positive previous history had LRTI while $10(21.7 \%)$ children had URTI. $31.7 \%$ of the children had previous episodes of ARI. Of the 145 children in the present study, only 16 children had a positive family history of ARI while 129 children children had no relation to family history. Among the 16 children, 15 (93.7\%) children had LRTI while 1 (6.3\%) children had URTI. 11\% of the children had positive family history of ARI.

TABLE 5: Distribution of children in relation to exclusive breast feeding, previous episodes and positive family history

\begin{tabular}{|c|c|c|c|}
\hline Risk factors & Total & LRTI & URTI \\
\hline $\begin{array}{c}\text { Not Exclusively Breast } \\
\text { fed }\end{array}$ & 32 & $24(75 \%)$ & $10(21.7 \%)$ \\
\hline $\begin{array}{c}\text { Positive Previous History } \\
\text { Of ARI }\end{array}$ & $46(31.7 \%)$ & $36(78.3 \%)$ & $1(6.3 \%)$ \\
\hline $\begin{array}{c}\text { Positive Family History } \\
\text { Of ARI }\end{array}$ & $16(11 \%)$ & $15(93.7 \%)$ & \\
\hline
\end{tabular}

\section{Discussion}

The present study is a cross-sectional study that included 145 children, among which 92 (63.4\%) were male children while $53(36.6 \%)$ were female children. The male : female ratio being 1.7:1.

ARI Incidence: In the present study, $69.7 \%$ children (101) had LRTI while $30.3 \%$ children had URTI. Similar incidence was reported by Singh and Nayar [11] who observed the highest prevalence of LRTI (0.07episodes/child/year). While Chabra et al and Zaman et al observed a higher incidence of AURI than ALRI $[12,13]$.
The higher incidence could be due to the environmental factors and over crowding.

ARI and Gender: In our study, 63.3\% male children had ARI while $36.6 \%$ female children had ARI.

$68.4 \%$ male children had LRTI and 52.3\% male children had URTI, while $31.6 \%$ female children had LRTI and $47.7 \%$ female children had URTI.

In both cases, male children had higher incidence of ARI (LRTI and URTI) compared to female children. 
This could be compared with studies done by Rahman and Rahman et al who observed $14.9 \%$ incidence in male children and $14.4 \%$ incidence in female children [14]. Anand Krishnan et al observed that boys had higher hospitalization rate due to ARI than girls [15]. While studies by Chabra et al and Islam et al observed the ARI incidence to be higher in girls than boys $[12,16]$. The probable reason could be that boys are more susceptible for the infection than girls because they are more exposed to the cross infections.

ARI and Age: Our study showed $46.2 \%$ children of the age group 6-12 months with the highest incidence of ARI and lowest in the age group of 37-48 months and 61-72 months $(6.2 \%)$. The highest incidence in relation to ARI control programme was observed in the age group of 13-72 months and least among 6 months. This could be compared with a study done by Islam et al who observed the incidence to be $26.2 \%$ and more common among infants and females [16]. Chabra et al and Mathew J L et al showed the highest incidence among infants less than 2 months [12,17]. Tambe MP et al observed a higher incidence in the age group of 6 months-2 years [18]. Vanthanopas K et al observed the highest ARI incidence among 6-11 months and lowest among 48-59 months [19].

Since the breast fed children are protective against some viral or bacterial agents due to maternal antibodies in the first 6 months of life. Concurrent initiation of weaning may predispose nutritional deficiencies and subsequent susceptibility to most infections, including ARI. The high ARI incidence found in children of 2-3 year age group may be due to their greater exposure to environmental factors.

ARI and Immunization Status: In the present study, $20.7 \%$ children were either partially immunized or not immunized. In such children LRTI was more common than URTI. Immunization status was inappropriate in male children than female children.

Studies that have shown association between immunization status and ARI were done by Savitha M $\mathrm{R}$ et al [20], Mathew J L et al[17], Broor S et al [21] and Prajapati B et al[22].

ARI and Malnutrition: $31.7 \%$ children were found to be malnourished. $21.4 \%$ had Grade 1 malnutrition, 9\% had Grade 2 and $1.4 \%$ had Grade 4 malnutrition. The malnutrition was more common among LRTI children than URTI.
Similar studies done by Savitha M R et al have shown a strong association of ARI with malnutrition [20]. Meanwhile Broor S et al studied an association of ARI with severe malnutrition [21].

Thymolymphatic depletion can happen in malnourished children. This causes defective cell mediated immunity which leads to severe gram negative infections and sepsis.

ARI and Exclusive Breast Feeding: In the present study, 32 children were not exclusively breast fed. Among them 24 (75\%) had LRTI while 8 (25\%) had URTI. Among the 32 children who were not breast fed, $26(81.3 \%)$ were male children while $6(18.7 \%)$ were female children. Association of ARI with lack of proper breast feeding practices were observed by studies done by Mathew J L et al [17], Savitha M R et al [20], Broor $\mathrm{S}$ et al [21], Prajapati B et al[22], Kaushik P V et al [23] and Rohit B et al[24]

ARI and Previous Episodes: In the present study, 46 $(31.7 \%)$ children had history of previous episodes of ARI. $36(78.3 \%)$ children with a positive previous history had LRTI while $10(21.7 \%)$ children had URTI.

A study done in Meerut district by Kaushik P V et al showed $42.25 \%$ incidence of ARI in children with a previous episode of ARI [23].

Among other literature reviewed, not many have considered this variable.

ARI and Family History: Of the 145 children in this study, $16(11.0 \%)$ children had a positive family Among the 16 children, 15 (93.7\%) children had LRTI while $1(6.3 \%)$ children had URTI. Similar results have been observed by Broor $\mathrm{S}$ et al and Leeder S R et al[21,25]. In a study by Biswas et al[26], Nafstad P et al[27] and Peat $\mathrm{J} \mathrm{K}$ et al[28], an association of ARI with parenteral smoking habit has been observed.

Children tend to stay in close contact with the family members, which makes them more vulnerable to contract communicable diseases.

\section{Limitations}

Not all the risk factors associated with ARI could be assessed.

Follow up was not proper in the admitted children.

$>$ Exclusive breast feeding was not followed by the mother and early weaning was done. 


\section{Conclusion}

$>$ Breast fed children have a lower incidence of ARI.

$>$ Better nutritional status reduce the ARI incidence.

$>$ Regular and complete immunization lower the ARI incidence.

$>$ Family history of ARI can predispose to the disease in children.

$>$ There has a been a relation to previous episodes of ARI found in this study.

Increased global awareness regarding ARI has culminated in the initiation of a standard strategy of case identification using simple clinical signs and symptoms, and empiric antibiotic treatment and this approach has been organized by the WHO [29].

Thus community organizations must promote and make efforts to improve the nutritional status, encourage mothers for proper breast feeding practices and give complete immunization in children.

Funding: Nil, Conflict of interest: None initiated, Perission from IRB: Yes

\section{References}

1. Kabra S K. Disorders of Respiratory System.In:Paul K Vinod, Bagga Arvind. Ghai Essential Pediatrics. $8^{\text {th }}$ ed. New Delhi:CBS Publ;2013.p.371-91.

2. WHO (1999), Health situation in the South-east Asia Region 1994-1997, Regional office for SEAR, New Delhi.

3. Govt. of India (2014), National Health Profile 2013, DGHS, Ministry of Health and Family Welfare, New Delhi.

4. Tambe MP, Shivaram C, Chandrashekhar Y. Acute respiratory infection in children: a survey in the rural community. Indian J Med Sci. 1999 Jun;53(6):249-53.

5. Singh MP, Nayar S. Magnitude of acute respiratory infections in under five children. J Commun Dis. 1996 Dec;28(4):273-8.

6. Denny FW Jr. The clinical impact of human respiratory virus infections. Am J Respir Crit Care Med. 1995 Oct;152(4 Pt 2):S4-12.

7. Hortal M., Mogdasy C., Russi J. C., Deleon C., Suarez A.Microbial Agents Associated with Pneumonia in Children from Uruguay. Reviews of Infectious Diseases. 1990;12(Suppl. 8):S915-22.

8. Kapoor SK, Reddaiah VP, Murthy GV. Knowledge, attitude and practices regarding acute respiratory infections. Indian J Pediatr. 1990 Jul-Aug;57(4):533-5.

9. Park K. Acute Respiratory Infection. Park's textbook of preventive and social medicine. $23^{\text {rd }}$ ed. Jabalpur. Banarsidas Bhanot:2015.p167-73

10. Prajapati B, Talsania NJ, Lala MK, Sonalia KN. Epidemiological profile of acute respiratory infections (ARI) in under five age group of children in urban and rural communities of Ahmedabad district, Gujarat. Int J Med Sci Public Health. 2012;1(2):52-58.

11. Singh MP, Nayar S. Magnitude of acute respiratory infections in under five children. J Commun Dis. 1996 Dec; 28(4):273-8.

12. Chhabra P, Garg S, Mittal SK, Satyanarayan L, Mehra M, Sharma N. Magnitude of acute respiratory infections in under five. Indian Pediatr. 1993 Nov;30 (11): 1315-9.

13. Zaman $\mathrm{K}$, et al. Acute respiratory infections in children: A community based longitudinal study in rural Bangladesh. Journal of Tropical Paediatrics. 1997; 43:133-36.

14. Rahman MM, Rahman AM. Prevalence of acute respiratory tract infection and its risk factors in under five children. Bangladesh Med Res Counc Bull. 1997 Aug; 23(2):47-50.

15. Krishnan A et al. Epidemiology of acute respiratory infections in children- preliminary results of a cohort in a rural north Indian community. BMC Infectious Diseases. 2015:15:462.

16. Islam F, Sarma R, Debroy A, Kar S, Pal R. Profiling acute respiratory tract infections in children from assam, India. J Glob Infect Dis. 2013 Jan;5(1):8-14. doi: 10. 4103 /0974-777X.107167.

17. Mathew JL, Patwari AK, Gupta P, Shah D, Gera T, Gogia S, Mohan P, Panda R, Menon S. Acute respiratory infection and pneumonia in India: a systematic review of literature for advocacy and action: 
UNICEF-PHFI series on newborn and child health, India. Indian Pediatr. 2011 Mar;48(3):191-218.

18. Tambe MP, Shivaram C, Chandrashekhar Y. Acute respiratory infection in children: a survey in the rural community. Indian J Med Sci. 1999 Jun;53(6):249-53.

19. Vathanophas K, Sangchai R, Raktham S, Pariyanonda A, Thangsuvan J, Bunyaratabhandu P, Athipanyakom S, Suwanjutha S, Jayanetra P, Wasi C, et al. A community-based study of acute respiratory tract infection in Thai children. Rev Infect Dis. 1990 NovDec; 12 Suppl 8:S957-65.

20. Savitha MR, Nandeeshwara SB, Pradeep Kumar MJ, ul-Haque F, Raju CK. Modifiable risk factors for acute lower respiratory tract infections. Indian J Pediatr. 2007 May;74(5):477-82.

21. Broor S, Pandey RM, Ghosh M, Maitreyi RS, Lodha R, Singhal T, Kabra SK. Risk factors for severe acute lower respiratory tract infection in under-five children. Indian Pediatr. 2001 Dec;38(12):1361-9.

22. Prajapati B, Talsania NJ, Sonalia KN. A study on prevalence of acute respiratory tract infections (ARI) in under five children in urban and rural communities of Ahmedabad district, Gujarat. Natl J Community Med. 2011;2:255-9.

23. Kaushik PV, Singh JV, Bhatnagar M, Garg SK, Chopra H. Nutritional correlates of acute respiratory infections. Indian J Matern Child Health. 1995 JulSep;6(3):71-2.

24. Rohit B et al. The study of frequency, risk factors and protective role of breastfeeding against acute respiratory tract infections in infants under one year of age: a community based, prospective, longitudinal, observational study. Proceedings from Karnataka State Paediatrics Conference, 2005 29-30; Gulbarga, India.

25. Leeder SR, Corkhill R, Irwig LM, Holland WW, Colley JR (1976) Influences of family factors on the incidence of lower respiratory illness during the first year of life. Br J Prev Soc Med 30: 203-212.

26. Biswas A, Biswas R, Manna B, Dutta K. Risk factors of acute respiratory infections in underfives of urban slum community. Indian J Public Health. 1999 Apr-Jun;43(2):73-5.

27. Nafstad P, Jaakkola JJ, Hagen JA, Botten G, Kongerud J. Breastfeeding, maternal smoking and lower respiratory tract infections. Eur Respir J. 1996 Dec; 9 (12):2623-9.

28. Peat JK, Keena V, Harakeh Z, Marks G. Parental smoking and respiratory tract infections in children. Paediatr Respir Rev. 2001 Sep;2(3):207-13

29. A programme for controlling acute respiratory infections in children: Memorandum from a WHO meeting. Bull World Health Organ. 1984;62(1):47-58.

\section{How to cite this article?}

Shivaprakash NC, Kutty DN. Magnitude of acute respiratory infections in 6 months- 6 years in a rural hospital in B G Nagara: a cross-sectional study. J PediatrRes.2017;4(03):224-230.doi:10. 17511/ijpr.2017.i03.05. 